\title{
PENGARUH GAYA KEPEMIMPINAN TRANSFORMASIONAL DAN TRANSAKSIONAL TERHADAP KINERJA BAWAHAN MELALUI KEPUASAN KERJA
}

\author{
Sardi $^{1}$ \\ ${ }^{1}$ SMK Muhammadiyah Pakem \\ Pak.sardi.umy@gmail.com
}

\begin{abstract}
The purpose of this study is to investigate whether transformational and transactional leadership styles have an impact on subordinate performance. Also we want to analyze the effect of job satisfaction as a mediating role.

The study was conducted at SMK Muhammadiyah Pakem and SMK Muhammadiyah 1

Moyudan, Sleman. The number of samples was 110 respondents(teachers and school employees). Structural Equation Modeling (SEM) analysis was used to analyze the data. The results showed that the transformational leadership style did not have a significant influence on subordinate performance while transactional one influenced positively. The transformational leadership style had a significant influence on job satisfaction. The result of the transactional leadership style on job satisfaction was negative, while job satisfaction had a very significant influence on subordinate performance. Based on these studies, it was recommended that the principal should apply a combination of both Transformational and Transactional leadership styles in accordance with the situation and the nature of the particular task assigned to the employee. In addition, Transactional leadership style is more preferable in improving employee performance to reach optimal organizational performance.
\end{abstract}

Keywords : Transformational Leadership, Transactional, Satisfaction, Performance.

() 2017 JBTI. All rights reserved

Article history : received 17 Feb 2017; revised 10 Mar 2017; accepted 20 Apr 2017

\section{PENDAHULUAN}

Abad dua puluh satu, zamannya melibatkan gaya kepemimpinan transformasional dan transaksional. Ini tidak lagi didasarkan pada sifat, perilaku dan situasi tertentu tetapi berdasarkan kemampuan pemimpin menekankan perubahan komprehensif berkaitan dengan kepemimpinan dalam abad 21 (Bass, 2005).

Seorang pemimpin dikatakan transformasional ketika dia mampu mengilhami bawahannya untuk menerima visi organisasi sebagai miliknya selagi berusaha untuk meningkatkan nilai-nilai organisasinya. Namun ada kontradiksi mengenai dampak gaya kepemimpinan transaksional dan transformasional terhadap kinerja organisasi. Beberapa studi tertentu (Rejas, Ponce, Almonte \& Ponce 2006) telah mengindikasikan bahwa kepemimpinan transformasional memiliki dampak positif pada kinerja sementara kepemimpinan transaksional berdampak negatif. Penelitian lain yang 
dilakukan di Nigeria oleh Obiwuru, Okwu, Akpa \& Nwankere, 2011 menyatakan bahwa kepemimpinan transaksional memiliki pengaruh positif yang signifikan terhadap kinerja, gaya kepemimpinan transformasional memiliki pengaruh positif namun tidak signifikan terhadap kinerja. Oleh karena itu, penelitian ini bertujuan untuk menyelidiki secara langsung dampak aktual gaya kepemimpinan transaksional dan transformasional di sektor pendidikan dalam upaya peningkatan kepuasan kerja dan akhirnya menghasilkan kinerja pegawai yang lebih tinggi.

Berdasarkan uraian latar belakang di atas, maka yang menjadi fokus masalah dalam penelitian ini sebagai berikut :

1. Bagaimanakah pengaruh gaya kepemimpinan transformasional terhadap kinerja bawahan di SMK Muhammadiyah Pakem dan SMK Muhammadiyah 1 Moyudan?

2. Bagaimanakah pengaruh gaya kepemimpinan transaksional terhadap kinerja bawahan di SMK Muhammadiyah Pakem dan SMK Muhammadiyah 1 Moyudan?

3. Bagaimanakah pengaruh kepuasan kerja terhadap kin erja bawahan di SMK Muhammadiyah Pakem dan SMK Muhammadiyah 1 Moyudan?

4. Bagaimanakah pengaruh gaya kepemimpinan transaksional terhadap kepuasan kerja di SMK Muhammadiyah Pakem dan SMK Muhammadiyah 1 Moyudan?

5. Bagaimanakah pengaruh gaya kepemimpinan transformasional terhadap kepuasan kerja di SMK Muhammadiyah Pakem dan SMK Muhammadiyah 1 Moyudan?

\section{KAJIAN TEORI}

Masalah kepemimpinan telah lahir bersamaan dengan dimulainya sejarah manusia, yaitu sejak manusia menyadari pentingnya hidup berkelompok untuk mencapai tujuan bersama. Mereka membutuhkan seseorang atau beberapa orang yang mempunyai kelebihan-kelebihan daripada yang lain. Hal ini tidak dapat hindari karena manusia selalu mempunyai keterbatasan dan kelebihan-kelebihan tertentu.

Dalam dua dasawarsa terakhir, konsep transaksional (transactional leadership) dan transformasional (transformational leadership) berkembang dan mendapat perhatian banyak kalangan akademisi maupun praktisi (Locander et.al., 2002; Yammarino et.al.,1993). Hal ini menurut Humphreys (2002) maupun Liu et.al. (2003) disebabkan konsep yang dipopulerkan oleh Bass pada tahun 1985, yang mana konsep ini mampu mengakomodasi konsep kepemimpinan yang mempunyai spektrum luas, termasuk mencakup pendekatan perilaku, pendekatan situasional, sekaligus pendekatan kontingensi.

\section{A. Kepemimpinan Transformasional}

Bass et.al (2003) serta Humphreys (2002) menjelaskan kemampuan pemimpin transformasional mengubah sistem nilai bawahan demi mencapai tujuan diperoleh dengan mengembangkan salah satu atau seluruh faktor yang merupakan dimensi kepemimpinan transformasional, yaitu : karisma (kemudian diubah menjadi pengaruh ideal atau idealized influence), inspirasi (inspirational motivation), pengembangan intelektual (intellectual stimulation), dan perhatian pribadi (individualized consideration).

Idealized influence menurut Sarros dan Santora (2001) merupakan perilaku (behavior) yang berupaya mendorong bawahan untuk menjadikan pemimpin mereka sebagai panutan (role model). Pada mulanya, dimensi ini dinamakan karisma, namun karena mendapat banyak kritik maka istilah karisma diubah menjadi pengaruh ideal atau visi. Idealized influence merupakan dimensi 
terpenting kepemimpinan transformasional Karena memberikan inspirasi dan membangkitkan motivasi bawahan (secara emosional) untuk menyingkirkan kepentingan pribadi demi pencapaian tujuan bersama. (Humphreys, 2002; Rafferty \& Griffin, 2004).

Inspirational motivation menurut Humphreys (2002) serta Rafferty dan Griffin (2004) memiliki korelasi yang erat dengan idealized influence. Seperti dijelaskan sebelumnya, pemimpin transformasional memberi inspirasi kepada bawahan untuk memusatkan perhatian pada tujuan bersama dan melupakan kepentingan pribadi. Inspirasi dapat diartikan sebagai tindakan atau kekuatan untuk menggerakkan emosi dan daya pikir orang lain (Rafferty \& Griffin, 2004). Pemimpin memotivasi bawahan akan arti penting visi dan misi organisasi sehingga seluruh bawahannya terdorong untuk memiliki visi yang sama.

Intellectual stimulation, merupakan faktor penting kepemimpinan transformasional yang jarang memperoleh perhatian (Rafferty \& Griffin, 2004). Intellectual stimulation merupakan perilaku yang berupaya mendorong perhatian dan kesadaran bawahan akan permasalahan yang dihadapi. Pemimpin kemudian berusaha mengembangkan kemampuan bawahan untuk menyelesaikan permasalahan dengan pendekatan - pendekatan atau perspektif baru. Dampak intellectual stimulation dapat dilihat dari peningkatan kemampuan bawahan dalam memahami dan menganalisis permasalahan serta kualitas pemecahan masalah (problem solving quality) yang ditawarkan (Rafferty \& Griffin, 2004; Yammarino et.al., 1993).

Individualized consideration atau perhatian pribadi. Individualized consideration mengarah pada pemahaman dan perhatian pemimpin pada potensi dan kemampuan yang dimiliki oleh setiap bawahannya. Pemimpin menyadari perbedaan kemampuan, potensi, dan juga kebutuhan bawahan. Pemimpin memandang setiap bawahannya sebagai aset organisasi. Oleh sebab itu, pemahaman pemimpin akan potensi dan kemampuan setiap bawahan memudahkannya membina dan mengarahkan potensi dan kemampuan terbaik setiap bawahan (Bass et.al., 2003; Sarros \& Santora,2001; Yammarino et.al., 1993.

\section{B. Kepemimpinan Transaksional}

Kepemimpinan transaksional menurut beberapa pakar memiliki dua karakter yang dinamakan contingent reward dan management by exception. Pemimpin transaksional yang mempunyai karakter contingent reward akan menjelaskan tujuan dan sasaran yang hendak dicapainya dan mengarahkan bawahan untuk mencapainya. Besar kecilnya imbalan (reward) akan tergantung pada (contingent) sejauhmana bawahan mencapai tujuan dan sasaran tersebut (Bass et.al., 2003; Humphreys, 2002; Yammarino et.al.,1993). Sedangkan pemimpin transaksional berkarakter management by exception dapat dibagi lagi ke dalam dua sifat, yaitu aktif dan pasif.

\section{Kinerja}

Armstrong dan Baron dalam Wibowo (2007 : 2) menyampaikan bahwa : "Kinerja (performance) adalah berhubungan dengan cara melakukan pekerjaan dan hasil yang dicapai dari pekerjaan tersebut. Kinerja merupakan hasil pekerjaan yang mempunyai hubungan kuat dengan tujuan strategis organisasi, kepuasan konsumen dan memberikan kontribusi ekonomi". Menurut Siswanto Bejo (2005 : 195) prestasi kerja adalah : Hasil kerja yang dicapai oleh seorang tenaga kerja dalam melaksanakan tugas dan pekerjaan yang dibebankan kepadanya. Pada umumnya prestasi kerja seorang tenaga kerja antara lain dipengaruhi oleh kecakapan, keterampilan, pengalaman, kesanggupan tenaga kerja yang bersangkutan. 


\section{Kepuasan Kerja}

Kreitner \& Kinichi (2005), menyampaikan lima model kepuasan kerja yaitu; Pertama pemenuhan kebutuhan, model ini menjelaskan bahwa kepuasan ditentukan oleh karakteristik dari sebuah pekerjaan yang memungkinkan seseorang dapat memenuhi kebutuhannya. Kedua ketidak cocokan, model ini menjelaskan bahwa kepuasan adalah hasil dari harapan yang terpenuhi. Ketiga pencapaian nilai, model ini menjelaskan bahwa kepuasan berasal dari persepsi bahwa suatu pekerjaan memungkinkan untuk pemenuhan nilai-nilai kerja yang penting dari individu. Keempat persamaan, model ini kepuasan adalah suatu fungsi dari bagaimana seorang individu diperlakukan ditempat kerja. Kelima watak/genetik, model ini berusaha menjelaskan beberapa orang merasa puas dengan situasi dan kondisi kerja tertentu, namun sebagian lagi merasa tidak puas dengan kondisi tersebut.

\section{E. Kerangka Pemikiran dan Hipotesis}

\section{Model Penelitian}

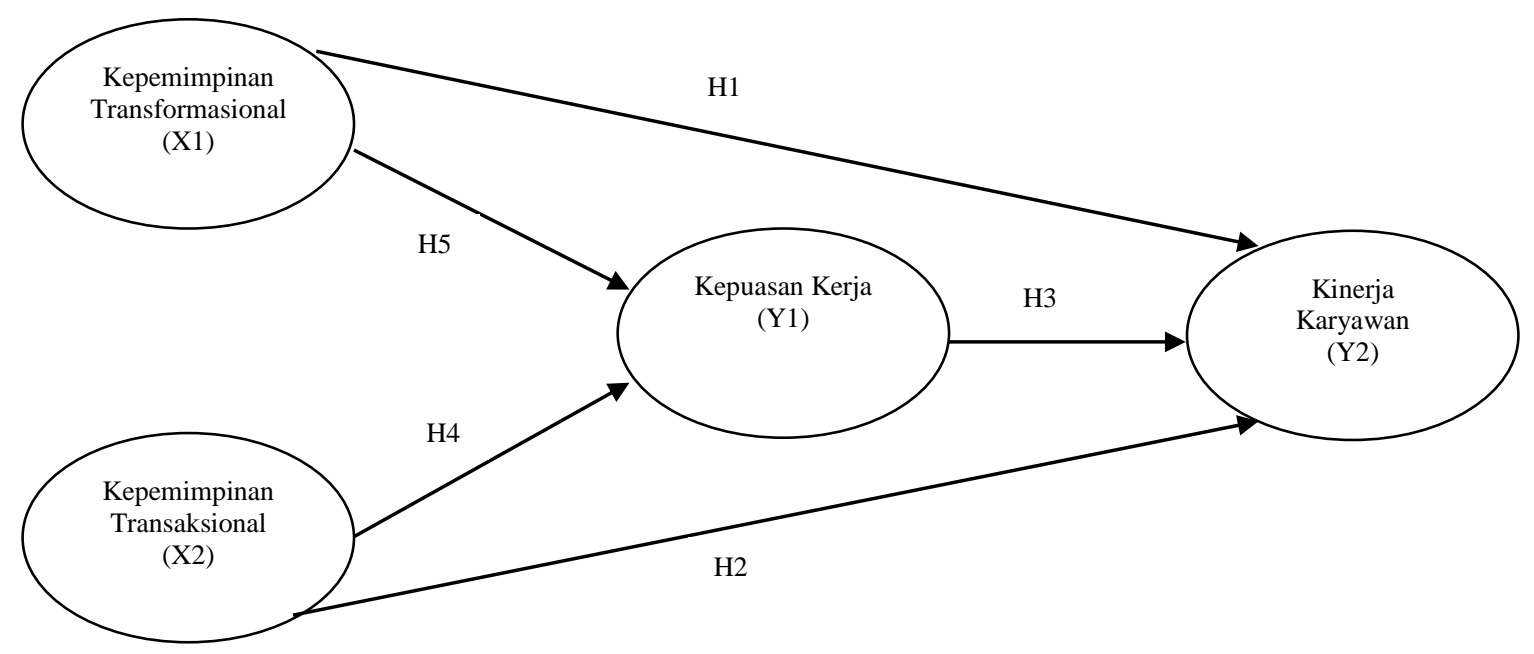

Gambar 1. Model Kepemimpinan, Kepuasan dan Kinerja

Sumber : Paracha et al (2012)

\section{F. Hipotesis}

Berdasarkan rumusan masalah, tujuan penelitian, kajian pustaka serta kerangka konseptual yang telah diuraikan sebelumnya, maka hipotesis yang diajukan dalam penelitian, adalah sebagai berikut:

1. Gaya kepemimpinan transformasional berpengaruh terhadap kinerja bawahan di SMK Muhammadiyah Pakem dan SMK Muhammadiyah 1 Moyudan.

2. Gaya kepemimpinan transaksional berpengaruh terhadap kinerja bawahan di SMK Muhammadiyah Pakem dan SMK Muhammadiyah 1 Moyudan.

3. Kepuasan kerja berpengaruh terhadap kinerja bawahan di SMK Muhammadiyah Pakem dan SMK Muhammadiyah 1 Moyudan.

4. Gaya kepemimpinan transaksional berpengaruh terhadap kepuasan kerja kinerja karyawan di SMK Muhammadiyah Pakem dan SMK Muhammadiyah 1 Moyudan.

5. Gaya kepemimpinan transformasional berpengaruh terhadap Kepuasan kerja di SMK Muhammadiyah dan SMK Muhammadiyah 1 Moyudan. 


\section{METODE PENELITIAN}

Jenis penelitian yang digunakan adalah penelitian eksplanatif asosiatif untuk mengetahui hubungan antara dua atau lebih variabel terhadap hubungan kausalitas antara variabel. Lokasi penelitian dilakuakan di SMK Muhammadiyah Pakem dan SMK Muhammadiyah 1 Moyudan. Waktu penelitian ini dilaksanakan pada akhir bulan februari sampai dengan 10 maret 2017. Jumlah sampel pada penelitian ini adalah 110 orang yang terdiri dari guru dan karyawan. Penelitian menggunakan teknik purposive sampling dengan kriteria-kriteria yang dikehendaki oleh peneliti dan convenience sampling berdasarkan pada kemudahan. Metode pengumpulan data menggunakan kuesioner skala Likert sebagai instrument pengumpulan data primer. Model dalam penelitian ini adalah model kausalitas atau hubungan pengaruh. Variabel penelitian ini dikelompokkan menjadi 3 (tiga) variabel.

A. Variabel bebas), yaitu:

1. Variabel kepemimpinan transformasional (X1), dengan indikator: attributed Charism, idealized influence, inspirational motivation, intellectual stimulation, individualized consideration (Bass dan Avolio, 2003).

2. Variabel transaksional) (X2), dengan indikator: reward kontinjen, manajemen dengan pengecualian dan manajemen aktif dengan pengecualian pasif (Teori adaptasi Bass dan Avolio, 2003).

B. Variabel Intervensi, yaitu variabel Kepuasan kerja (Y1), yang bisa didefinisikan sebagai sikap emosional yang menyenangkan dan mencintai pekerjaannya. Sikap ini dicerminkan oleh moral kerja, kedisiplinan, dan prestasi kerja. Kepuasan kerja dinikmati dalam pekerjaan, luar pekerjaan, dan kombinasi antara keduanya. (Malayu S.P. Hasibuan 2006:202).

C. Variabel dependen, yaitu variabel kinerja bawahan (Y2), dengan indikator: hasil kerja secara kualitas dan kuantitas yang dicapai oleh seorang pegawai dalam melaksanakan tugasnya sesuai dengan tanggung jawab yang diberikan kepadanya. (Anwar Prabu Mangkunegara 2009:67).

Untuk pengujian hipotesis dalam penelitian ini yaitu tekhnik analisis dengan menggunakan SEM atau Struktural Equation Modelling yang didukung oleh software AMOS 21. SEM dipilih karena ia merupakan teknik analisis multivariat yang merupakan gabungan analisis regresi, analisis jalur, analisis faktor dan model struktural.

\section{ANALISIS DATA DAN HASIL PENELITIAN}

\section{A. Hasil Analisis Data}

\section{Uji Normalitas}

Evaluasi normalitas data dilakukan dengan menggunakan nilai critical ratio skewness value sebesar $\pm 2,58$ pada tingkat signifikansi $0,01(1 \%)$. Data dikatakan berdistribusi normal jika nilai critical ratio skewness value di bawah $\pm 2,58$ (Ghozali, 2005). Hasil uji normalitas setelah data diolah sebagai berikut: 


\section{Tabel .1}

Hasil Uji Normalitas

\begin{tabular}{|c|c|c|c|c|c|c|}
\hline Variable & $\min$ & $\max$ & skew & c.r. & kurtosis & c.r. \\
\hline KB10 & 1.000 & 4.000 & -.104 & -.437 & -.218 & -.460 \\
\hline KB9 & 2.000 & 4.000 & -.050 & -.211 & -.394 & -.832 \\
\hline KB8 & 2.000 & 4.000 & .038 & .160 & .336 & .709 \\
\hline KB7 & 2.000 & 4.000 & .030 & .127 & -.054 & -.114 \\
\hline KB6 & 2.000 & 4.000 & .041 & .173 & .444 & .938 \\
\hline KB5 & 2.000 & 4.000 & .038 & .160 & .336 & .709 \\
\hline KB4 & 2.000 & 4.000 & .082 & .344 & -.421 & -.888 \\
\hline KB3 & 2.000 & 4.000 & .093 & .392 & .665 & 1.405 \\
\hline KK15 & 2.000 & 4.000 & -.070 & -.297 & -.363 & -.767 \\
\hline KK12 & 2.000 & 4.000 & -.137 & -.578 & -.494 & -1.044 \\
\hline KK11 & 2.000 & 4.000 & -.287 & -1.210 & -.646 & -1.363 \\
\hline KK10 & 2.000 & 4.000 & -.209 & -.882 & -.588 & -1.242 \\
\hline KK7 & 2.000 & 4.000 & -.001 & -.005 & -.292 & -.617 \\
\hline KK6 & 2.000 & 4.000 & -.073 & -.308 & -.428 & -.903 \\
\hline KK3 & 1.000 & 4.000 & .158 & .667 & -.737 & -1.557 \\
\hline KK2 & 1.000 & 4.000 & .308 & 1.300 & -.868 & -1.832 \\
\hline KK1 & 2.000 & 4.000 & -.094 & -.398 & -.408 & -.862 \\
\hline KTS2 & 1.000 & 4.000 & -.173 & -.730 & .185 & .390 \\
\hline KTS4 & 1.000 & 4.000 & -.271 & - & .740 & 1.563 \\
\hline KTS5 & 1.000 & 4.000 & -.302 & - & .834 & 1.760 \\
\hline KTS6 & 1.000 & 4.000 & .245 & $1.03 \phi$ & -.554 & -1.170 \\
\hline KTS7 & .000 & 4.000 & -.554 & - & .749 & 1.581 \\
\hline KTS9 & 1.000 & 4.000 & -.238 & - & .521 & 1.100 \\
\hline KTF3 & 2.000 & 4.000 & -.051 & -.217 & -.501 & -1.058 \\
\hline KTF4 & 2.000 & 4.000 & .046 & .196 & -.073 & -.153 \\
\hline KTF5 & 2.000 & 4.000 & .010 & .041 & .055 & .115 \\
\hline KTF7 & 2.000 & 4.000 & -.229 & -.967 & -.678 & -1.431 \\
\hline KTF8 & 2.000 & 4.000 & .000 & .000 & -.028 & -.059 \\
\hline KTF9 & 2.000 & 4.000 & -.010 & -.043 & -.723 & -1.527 \\
\hline KTF10 & 2.000 & 4.000 & -.218 & -.922 & -.743 & -1.570 \\
\hline
\end{tabular}




\begin{tabular}{|l|r|r|r|r|r|c|}
\hline KTF11 & 2.000 & 4.000 & -.064 & -.270 & -.760 & -1.605 \\
\hline KTF13 & 1.000 & 4.000 & -.213 & -.898 & .095 & .201 \\
\hline KTF14 & 2.000 & 4.000 & -.123 & -.519 & -.571 & -1.206 \\
\hline Multivariate & & & & & $\begin{array}{l}219.61 \\
8\end{array}$ & 23.633 \\
\hline
\end{tabular}

Sumber : Hasil olah data primer

Berdasarkan tabel diatas menunjukkan bahwa keseluruhan pertanyaan pada masingmasing variabel nilai $\mathrm{CR}< \pm 2,580$, maka data sudah normal.

\section{Uji Reliabilitas}

Reliabilitas adalah ukuran konsistensi internal dari indikator-indikator sebuah variabel bentukan yang menunjukkan derajat sampai dimana masing-masing indikator itu mengindikasikan sebuah variabel bentukan umum. Terdapat dua cara yang dapat digunakan, yaitu construct reliability dan variance extracted. Cut off dari construct reliability adalah 0,700 sedangkan Cut off dari variance extracted minimal 0,50 (Ghozali,2008).

Tabel 2.

Hasil Uji Reliabilitas

Construct Reliability dan Variance Extracted

\begin{tabular}{lrrl}
\hline Variabel & Nilai CR & Nilai VE & Keterangan \\
\hline Gaya kepempinan transformasional & 0,934 & 0,587 & Reliabel \\
Gaya kepempinan transaksional & 0,875 & 0,539 & Reliabel \\
Kepuasan Kerja & 0,934 & 0,614 & Reliabel \\
Kinerja Bawahan & 0,914 & 0,571 & Reliabel \\
\hline
\end{tabular}

Sumber : Hasil olah data primer

Berdasarkan tabel diatas menunjukkan bahwa nilai construct reliability (CR) variabel gaya kepempinan transformasional, gaya kepemimpinan transaksional, kepuasan kerja, kinerja bawahan semuanya diatas 0,700 , maka disimpulkan sudah realiabel.

Berdasarkan tabel diatas menunjukkan bahwa nilai variance extracted (VE) variabel gaya kepemimpinan transformasional, gaya kepempinan transaksional, kepuasan kerja, kinerja bawahan semuanya diatas 0,50 , maka disimpulkan sudah realiabel.

\section{Hasil Uji Goodness-of-fit-Model}

Kriteria-kriteria goodness-of-fit sebagai berikut:

Tabel 3.

Hasil Uji Kriteria-Kriteria Goodness-Of-Fit Setelah Modification Indices

\begin{tabular}{lll}
\hline Kriteria & Nilai rekomendasi & Nilai
\end{tabular}




\begin{tabular}{llll} 
Chi Square $\left(\mathrm{X}^{2}\right)$ & $<539,446\left(\mathrm{X}^{2}\right)$ tabel & 788,800 & Kurang baik \\
$\mathrm{X}^{2}$ Significance & $\geq 0,05$ & 0,000 & Kurang baik \\
CMIN/DF & $\leq 2$ & 1,685 & Baik \\
GFI & $\leq 0,90$ & 0,721 & Kurang baik \\
AGFI & $\leq 0,80$ & 0,665 & Kurang baik \\
TLI & $\leq 0,90$ & 0,867 & Marginal \\
NFI & $\leq 0,90$ & 0,758 & Kurang baik \\
CFI & $\leq 0,90$ & 0,882 & Marginal \\
RMSEA & $\leq 0,08$ & 0,080 & Baik \\
\hline
\end{tabular}

Sumber : Hasil olah data primer

Berdasarkan tabel diatas dapat dilihat bahwa model secara keseluruhan memperlihatkan tingkat kesesuaian yang kurang baik. Dengan demikian dapat bahwa hasil pengujian goodness of fit pada model standar yang dipakai dalam penelitian ini menunjukkan bahwa data yang diobservasi belum sesuai atau konsisten dengan teori atau model yang akan diuji. Namun ada beberapa yang sudah memenuhi syarat yaitu nilai CMIN/DF sebesar 1,685 $\leq 2$ disimpulkan baik dan nilai RMSEA $0,080 \leq 0,08$ disimpulkan baik serta nilai CFI sebesar $0,882 \leq 0,90$ disimpulkan marginal. Oleh karena dari hasil sudah ada beberapa yang memenuhi sesuai yang diharapkan, sehingga model yang diajukan dinilai cukup baik dan dapat diterima sebagai model yang sesuai dalam penelitian ini.

\section{Pengujian Hipotesis}

Uji statistik hubungan antar variable yang menjadi dasar dalam hipotesis penelitian telah diajukan. Uji statistik hasil pengolahan dengan SEM dilakukan dengan melihat tingkat signifikan hubungan antar variabel yang ditampakkan melalui nilai critical ratio (c.r) dan nilai significance probability masing-masing hubungan antar variabel. Proses pengujian statistik ini dapat dilihat pada tabel di bawah ini.

\section{Tabel 4.}

Hasil Estimasi Parameter Pengaruh Antar

Variabel Berdasarkan Model SEM.

\section{Regression Weights}

\begin{tabular}{lllrrrr}
\hline \multicolumn{1}{c}{ Variabel } & & Variabel & Estimate & \multicolumn{1}{c}{ S.E. } & \multicolumn{1}{c}{ C.R. } & P \\
\hline KK & $<--$ & KTF & .519 & .160 & 3.243 & .001 \\
KK & $<---$ & KTS & .120 & .158 & .760 & .447 \\
KB & $<---$ & KTF & .198 & .120 & 1.649 & .099 \\
KB & $<--$ & KK & .193 & .083 & 2.320 & .020 \\
KB & $<---$ & KTS & .339 & .119 & 2.843 & .004 \\
\hline
\end{tabular}

Sumber : Hasil olah data primer 
Mengacu pada hasil pen0gujian tahap akhir terhadap model keseluruhan, maka dapat dituliskan persamaan model matematik dalam bentuk Structural Equation Model (SEM) sebagai berikut :

$$
\begin{aligned}
& \mathrm{KK}=0,519 \mathrm{KTF}+0,120 \mathrm{KTS} \\
& \mathrm{KB}=0,198 \mathrm{KTF}+0,339 \mathrm{KTS}+0,193 \mathrm{KK} \text { Keterangan: } \\
& \mathrm{KK}=\text { Kepuasan Kerja } \\
& \mathrm{KB}=\text { Kinerja Bawahan } \\
& \mathrm{KTF}=\text { Gaya Kepemimpinan Transformasional } \\
& \mathrm{KTS}=\text { Gaya Kepemimpinan Transaksional }
\end{aligned}
$$

\section{B. Hasil Pengujian Hipotesis}

\section{Pengaruh Gaya Kepemimpinan Transformasional terhadap Kinerja Bawahan}

Hasil penelitian yang tertera pada tabel 4.1.5 menunjukkan bahwa variabel gaya kepemimpinan transformasional memiliki nilai estimate (nilai koefesien) sebesar 0,198 dengan nilai critical ratio (CR) sebesar 1,649 dan nilai significance probability sebesar 0,099 . Berdasarkan nilai estimate (nilai koefesien) sebesar 0,198 mempunyai nilai positif. Artinya apabila gaya kepemimpinan transformasional mengalami peningkatan maka kinerja bawahan juga mengalami peningkatan pula. Nilai critical ratio (CR) sebesar 1,649 dan nilai significance probability sebesar 0,099 >0,05 maka dikatakan tidak signifikan. Artinya tidak ada pengaruh yang signifikan gaya kepemimpinan transformasional terhadap kinerja bawahan.

\section{Pengaruh Gaya Kepemimpinan Transaksional terhadap Kinerja Bawahan}

Hasil penelitian yang tertera pada tabel tabel 4.15 menunjukkan bahwa variabel gaya kepemimpinan transaksional memiliki nilai estimate (nilai koefesien) sebesar 0,339 dengan nilai critical ratio (CR) sebesar 2,843 dan nilai significance probability sebesar 0,004. Berdasarkan nilai estimate (nilai koefesien) sebesar 0,339 mempunyai nilai positif. Artinya apabila gaya kepemimpinan transaksional mengalami peningkatan maka kinerja bawahan juga mengalami peningkatan pula. Nilai critical ratio (CR) sebesar 2,843 dan nilai significance probability sebesar $0,004<0,05$ maka dikatakan signifikan. Artinya ada pengaruh yang signifikan gaya kepemimpinan transaksional terhadap kinerja bawahan.

\section{Pengaruh Kepuasan Kerja terhadap Kinerja Bawahan}

Hasil penelitian yang tertera pada tabel tabel 4.1.5 menunjukkan bahwa variabel kepuasan kerja memiliki nilai estimate (nilai koefesien) sebesar 0,193 dengan nilai critical ratio (CR) sebesar 2,320 dan nilai significance probability sebesar 0,020. Berdasarkan nilai estimate (nilai koefesien) sebesar 0,193 mempunyai nilai positif. Artinya apabila kepuasan kerja mengalami peningkatan maka kinerja bawahan juga mengalami peningkatan pula. Nilai critical ratio (CR) sebesar 2,320 dan nilai significance probability sebesar 0,020<0,05 maka dikatakan signifikan. Artinya ada pengaruh yang signifikan kepuasan kerja terhadap kinerja bawahan.

\section{Pengaruh Gaya Kepemimpinan Transaksional terhadap Kepuasan Kerja}

Hasil penelitian yang tertera pada tabel tabel 4.1.5 menunjukkan bahwa variabel gaya kepemimpinan transaksional memiliki nilai estimate (nilai koefesien) sebesar 0,120 dengan nilai critical ratio $(\mathrm{CR})$ sebesar 0,760 dan nilai significance probability sebesar 0,447 . Berdasarkan nilai 
estimate (nilai koefesien) sebesar 0,760 mempunyai nilai positif. Artinya apabila gaya kepemimpinan transaksional mengalami peningkatan maka kepuasan kerja juga mengalami peningkatan pula. Nilai critical ratio (CR) sebesar 0,760 dan nilai significance probability sebesar $0,447>0,05$ maka dikatakan tidak signifikan. Artinya tidak ada pengaruh yang signifikan gaya kepemimpinan transaksional terhadap kepuasan kerja.

\section{Pengaruh Gaya Kepemimpinan Transformasional terhadap Kepuasan Kerja}

Hasil penelitian yang tertera pada tabel tabel 4.1.5 menunjukkan bahwa variabel gaya kepemimpinan transformasional memiliki nilai estimate (nilai koefesien) sebesar 0,519 dengan nilai critical ratio (CR) sebesar 3,243 dan nilai significance probability sebesar 0,001. Berdasarkan nilai estimate (nilai koefesien) sebesar 3,243 mempunyai nilai positif. Artinya apabila gaya kepemimpinan transformasional mengalami peningkatan maka kepuasan kerja juga mengalami peningkatan pula. Nilai critical ratio (CR) sebesar 3,243 dan nilai significance probability sebesar $0,001<0,05$ maka dikatakan signifikan. Artinya ada pengaruh yang signifikan gaya kepemimpinan transformasional terhadap kepuasan kerja.

\section{KESIMPULAN DAN SARAN}

\section{A. Kesimpulan}

Berdasarkan hasil dari analisis data dalam penelitian ini maka dapat ditarik kesimpulan sebagai berikut:

a. Dari hasil pengujian hipotesis ini menunjukkan bahwa variabel gaya kepemimpinan transformasional tidak memiliki pengaruh yang signifikan terhadap kinerja bawahan di SMK Muhammadiyah Pakem dan SMK Muhammadiyah 1 Moyudan.

b. Dari hasil pengujian hipotesis ini menunjukkan bahwa variabel gaya kepemimpinan transaksional memiliki pengaruh terhadap Kinerja bawahan di SMK Muhammadiyah Pakem dan SMK Muhammadiyah 1 Moyudan.

c. Dari hasil pengujian hipotesis ini menunjukkan bahwa variabel kepuasan kerja berpengaruh terhadap kinerja bawahan di SMK Muhammadiyah Pakem dan SMK Muhammadiyah 1 Moyudan.

d. Dari hasil pengujian hipotesis ini menunjukkan bahwa variabel gaya kepemimpinan transaksional tidak berpengaruh terhadap kepuasan kerja bawahan di SMK Muhammadiyah Pakem dan SMK Muhammadiyah 1 Moyudan.

e. Dari hasil pengujian hipotesis ini menunjukkan bahwa variabel gaya Kepemimpinan Transformasional berpengaruh terhadap kepuasan kerja bawahan di SMK Muhammadiyah Pakem dan SMK Muhammadiyah 1 Moyudan.

\section{B. Keterbatasan Penelitian}

Dalam melakukan penelitian ini, penulis memiliki beberapa keterbatasan maupun kelemahan. Adapun keterbatasan dan kelemahan yang ditemukan pada penelitian ini dapat dijadikan sumber bagi penelitian akan datang. Keterbatasan-keterbatasan yang ditemukan pada penelitian ini adalah:

1. Dalam melakukan penelitian ini peneliti hanya menguji karyawan di SMK Muhammadiyah Pakem dan SMK Muhammadiyah 1 Moyudan. Dengan demikian hasil dan implikasi manajerial dalam penelitian ini mungkin tidak sepenuhnya akurat apabila diterapkan pada sekolah di 
wilayah lain. Mungkin ada variabel lain di luar model penelitian yang juga berpengaruh dalam meningkatkan kinerja karyawan.

2. Penelitian ini hanya mengambil satu obyek penelitian yaitu pada SMK Muhammadiyah Pakem dan SMK Muhammadiyah 1 Moyudan dengan menggunakan sampel yang terbatas yaitu sebesar 110 orang responden sehingga kondisi yang berbeda jika dengan obyek sekolah yang berbeda, jumlah populasi yang lebih banyak dapat memberikan hasil yang berbeda pula.

\section{C.Saran}

Berdasarkan hasil keseluruhan dalam penelitian maka ada beberapa pandangan- pandangan peneliti yang sekiranya dapat diangkat sebagai saran untuk SMK Muhammadiyah Pakem dan SMK Muhammadiyah 1 Moyudan:

1. Kepala Sekolah hendaknya bisa menerapkan kombinasi kedua gaya kepemimpinan baik Transformasional maupun Transaksional sesuai dengan situasi dan sifat tugas tertentu yang ditugaskan ke karyawan.

2. Gaya kepemimpinan transaksional lebih berperan dalam meningkatkan kinerja karyawan. Dalam hal ini Kepala Sekolah harus mensosialisasikan dengan baik seluruh aturan, standar proses dan prosedur serta semua ketetapan yang berlaku pada karyawan sehingga dapat menjalankan kepemimpinannya dengan baik. Seorang pemimpin transaksional harus menunjukkan keahlian dalam bidang pekerjaannya dan menguasai permasalahan kerja bawahan sehingga mampu emberikan koreksi terhadap kesalahan yang dilakukan bawahan.

3. Melihat hasil penelitian bahwa kepuasan kerja merupakan variabel yang berpengaruh positif dalam mempengaruhi kinerja karyawan, maka sebaiknya Kepala Sekolah terus meningkatkan faktor-faktor yang mempengaruhi kepuasan kerja karyawan.

4. Bagi peneliti selanjutnya dapat melakukan uji ulang pada model yang digunakan saat ini pada sekolah yang berbeda dan menambah variabel-variabel lain yang mempengaruhi kinerja karyawan. Misalnya, kompensasi, budaya organisasi.

\section{DAFTAR PUSTAKA}

Bass, B.M., 1996, From Transactional to transformational Leadership: Learning to Share the Vision, Organizational Dynamic, 1990, dalam Steers, Porter \& Bigley, Motivation and leadership at Work, McGraw Hill International 6th Edition.

Bass, B.M., 1997, The Ethics of Transformational Leadership, Academy of Leadership Press, 1997 (dalam www. academy.umd.edu, 6 Nopember 2004)

Bass, B., dan Avolio, BJ., 2004, Improving Leadership Effectiveness through Transformational Leadership, California, USA 7 Sage.

Bass, B., 2005, Leadership and Performance Beyond Expectations. New York : The free Press.

Bejo, S., 2005, "Manajemen Tenaga Kerja Indonesia pendekatan Administratif dan Operasional". Jakarta : Bumi Aksara.

Ghozali, I., 2008, Model Persamaan Struktural : Konsep dan Aplikasi dengan program AMOS 16.0. Penerbit Universitas Diponegoro. Semarang.

Hasibuan, M. S. P., 2012, Manajemen Sumber Daya Manusia (Rev. Ed.) Jakarta : Bumi Aksara. 
Humphreys, J. H., 2002, Transformational leader behavior, proximity and successful services marketing : Journal of Services Marketing, Vol. 16,No.6, pp.487-502.

Kreitner, R dan Kinicki, A., 2005, Perilaku Organisasi, buku 1 dan 2, Jakarta : Salemba Empat.

Liu, W., D. P. Lepak, R. Takeuchi \& H.P. Sims., 2003, Matching leadership styles with employment modes: Strategic human resource management perspective. Human Resource Management Review.Vol. 13,pp. 127-152.

Mangkunegara, A. P., 2001, Manajemen Sumber Daya Manusia Perusahaan, Remaja Rosdakarya, Bandung.

Obiwuru, T. C., Okwu, A.T., Akpa, V. O., \& Nwankwere,I.A., 2011, Effects of Leadership Style on Organisational Performance: Journal of Business and Management Research, 1.1(7),100-111.

Paracha, M. Umer, Q, A., Mirza, A., ul-Hassan-Inam \& waqas, H., 2012, "Impact of Leadership Style (Transformational \& Transactional Leadership) On Employee Performance \& Mediating Role of Job Satisfaction" Study of Private School (Educator) In Pakistan. Global Journal of Management and Business Research. Volume 12 Issue 4 Version 1.0. 55-63.

Rafferty, A. E \& Griffin, M. A.,2004, Dimensions of Tranformational leadership: conceptual and empirical extensions. Leadership Quarterly.

Rejas, L.P., E.R. Ponce, M.D., Almonte dan J.R. Ponce., 2006, Transformational and Transactional Leadership: A Study of Their Influence in Small Companies. Revista Chilena de Ingeniería Vol. 14, No. 2, pp. 159-166.

Sarros, J.C. \& J.C. Santora., 2001, The transformational-transactional leadership model in practice,Leadership \& Organization Develeopment. Journal. Vol.22, No.8, pp. 383-393.

Tjahjono, H.K., 2015. Metode Penelitian Bisnis. VSM MM UMY

Tjahjono, H.K., 2015. Manajemen Sumberdaya Manusia. VSM MM UMY

Yammarino, F.J., Spangler, W.D \& Bass. B.M., 1993, Transformational leadership and performance: A longitudinal investigation. Leadership Quarterly, Vol.4, No.1, pp.81-102.

Wibowo., 2007, Manajemen Kinerja. Jakarta: PT. Raja Grafindo Persada. 